\title{
Use of epidemiology to strengthen Speech-Language and Hearing Sciences
}

Bárbara Niegia Garcia de Goulart(1)

(1) Universidade Federal do Rio Grande do Sul, Programa de Pós-graduação em Epidemiologia, Porto Alegre, RS, Brasil. Research support source: Conselho Nacional de Desenvolvimento Científico e Tecnológico (CNPq).

Conflict of interests: Nonexistent

\section{(c) (i)}

Received on : November 9, 2017 Accepted on: December 12, 2017

Mailing address:

Bárbara Goulart

Universidade Federal do Rio Grande do Sul

Ramiro Barcelos, 2400 - Santa Cecília

CEP: 90035-004 - Porto Alegre -

Rio Grande do Sul - Brasil

Email: bngoulart@gmail.com
Epidemiology is traditionally characterized as the study of factors associated with health and illness or diseases in the population; it is also known to potentially contribute to health management in the collective context.

Knowledge related to epidemiological assumptions, such as causality, association, risk, chance, bias, confounding, internal validity, external validity, sensitivity, specificity, predictive values, and statistical test applications supported by theoretical models that are related to the application of the epidemiological concepts provide important bases for the construction and strengthening of a science that has aspects such as reproducibility and leading to discussion beyond the human communication sciences. It additionally allows for an effective increase in quality and credibility beyond the self-recognition and self-identification of necessity and relevance.

It is imperative that we raise awareness of the most vulnerable populations to speech-language, swallowing and hearing disorders and the impact of these disorders on their lives in childhood, in learning, in social interaction, in work, in food, or even in the occurrence of comorbidities or death as well as of the costs and benefits of rehabilitation, progress in speech and language, and the costbenefit of these interventions.

These are attributions that researchers and scientists must undertake, in speech therapy groups or networks of collaboration with other researchers who incorporate this knowledge.

Potential sources of contact with such information are websites from wellknown universities such as McGill and McMaster in Canada, Equator Network, with free online books that are regularly updated as that published by the Centers for Disease Control $(C D C)^{1}$ and another funded by the World Health Organization ${ }^{2}$, and a series of free access publications from the British Medical Journal on epidemiology for the uninitiated ones (available at http://www.bmj.com/about-bmj/ resources-readers/publications / epidemiology-uninitiated / 1-what-epidemiology). A myriad of courses is available from free online platforms such as openLearn, and Youtube videos that explain in a didactic and simplified way the various concepts 
and applications of knowledge and present classic examples of this area of knowledge ${ }^{3}$.

However, clinicians should use epidemiological knowledge to develop their activities based on existing evidence, and it is critical for them to be well-informed about analytical reading of scientific articles, identification of research designs, biases, systematic errors, identification of exposures and endpoints studied, as well as internal and external validity of studies, degree of evidence and recommendations, among others.

It takes time to get training to meet these requirements, but it is necessary to start wherever you are, in the central cities or the inland, as more and more online technologies and free access become available to learn these skills.

Therefore, we must discuss this issue and recognize that our knowledge is incipient regarding research methodology, our studies lack up-to-date measures. We must count on support from epidemiology to effectively make a leap in quality in the studies that have been developed in the area, in order to gain recognition beyond our peers.

It is not the only way forward, but it is undoubtedly one of the paths that Speech-language and Hearing Sciences should follow.

\section{ACKNOWLEDGEMENTS}

To Heather Beckius for the English revision.

\section{REFERENCES}

1. Center of Disease Control and Prevention. Principles of epidemiology in public health practice: an introduction to applied epidemiology and biostatistics. 3.ed. Atlanta: CDC; 2011. Disponível em URL https://www.cdc.gov/ophss/csels/dsepd/ ss1978/index.html. Acessado em 08 nov 2017.

2. Bonita $R$, Beaglehole $R$, Kjellström $T$. Causalidade em epidemiologia. In: Epidemiologia Básica. 2.ed. Genebra: $\overline{\mathrm{OMS}}$; 2010. Disponível em http://whqlibdoc.who.int/ publications/2010/9788572888394_por.pdf. [acessado em 19 de outubro de 2017].

3. Kleinbaum DG. ActivEpi web. Disponível em URL http://www.activepi.com/ [acessado em 19 de agosto de 2016]. 